Pacific Journal of Mathematics

SCHAUDER BASES AND FIXED POINTS OF NONEXPANSIVE 


\title{
SCHAUDER BASES AND FIXED POINTS OF NONEXPANSIVE MAPPINGS
}

\author{
PAOLO M. SOARDI
}

A fixed point theorem is proved for nonexpansive mappings in Banach spaces which are isomorphic to spaces with certain boundedly complete bases.

1. Introduction. Suppose $X$ and $Y$ are isomorphic Banach spaces with $h\|\cdot\|_{Y} \leqq\|\cdot\|_{X} \leqq k\|\cdot\|_{Y}$, where $\|\cdot\|_{Y}$ and $\|\cdot\|_{X}$ denote the norms in $Y$ and $X$ respectively. Let $t=k h^{-1}$ (this notation will be kept fixed throughout the paper). Suppose also that every convex weakly compact (weak* compact, when $X$ is a dual Banach space) subset $K$ of $X$ has the fixed point property with respect to nonexpansive mappings (i.e., mappings $T: K \rightarrow K$ such that $\|T x-T y\|_{X} \leqq\|x-y\|_{X}$, for all $x, y \in K)$. It is not known in general whether, assuming $t$ sufficiently close to 1 , convex weakly compact (weak* compact) subsets of $Y$ have the same property (but see Bynum [1]).

In this paper we answer in the affirmative this question when $X$ has a Schauder basis $\left(b_{n}\right)$ which satisfies a condition introduced by Gossez and Lami Dozo [2]. For every positive integer $k$ and $x \in X$ set $U_{k}(x)=\sum_{n=1}^{k} f_{n}(x) b_{n}$, where $\left(f_{n}\right)$ denotes the associated system of linear functionals. We shall always assume that there exists a strictly increasing sequence $\left(k_{n}\right)$ with the following property:

for every $c>0$ there is $\rho>0$ such that whenever $x \in X$ and $n$ satisfy

$$
\begin{array}{r}
\left\|U_{k_{n}}(x)\right\|_{X}=1 \\
\left\|x-U_{k_{n}}(x)\right\|_{X} \geqq c
\end{array}
$$

then $\|x\|_{x} \geqq 1+\rho$.

It is easy to see (Lemma 1 below) that the above condition implies that the basis $\left(b_{n}\right)$ is boundedly complete, so that $X$ is a dual Banach space.

In the next sections it is proved that there exists $t_{0}>1$ such that for $t<t_{0}$ every weak* compact convex subset of $Y$ has the fixed point property with respect to nonexpansive mappings. For $t=1$ this follows easily from the results of Karlovitz [3], while for $t>1$ it can not be deduced from [3]. As a remarkable consequence we obtain that, in every Banach space $Y$ isomorphic to $l^{1}$ with $t<2$, weak* compact convex subsets have the fixed point property with respect to nonexpansive mappings. 
2. Properties of the space $X$.

Lemma 1. Suppose $X$ is a Banach space with a Schauder basis $\left(b_{n}\right)$ satisfying the assumptions of the above section. Then the basis $\left(b_{n}\right)$ is boundedly complete and $X$ is isomorphic to the dual of the Banach space generated by the system of the linear functionals $\left(f_{n}\right)$.

Proof. Suppose that $\left(a_{n}\right)$ is a sequence of scalars such that $\sup _{N}\left\|\sum_{n=1}^{N} a_{n} b_{n}\right\|_{X}<\infty$. Then, the same argument as in $[6$, p. 290291] implies that, for some subsequence $k_{n_{j}}, \sum_{n=1}^{k_{n_{j}}} a_{n} b_{n}$ converges to a point $x \in X$. Then, of course, $f_{n}(x)=a_{n}$ for every $n$, so that $\sum_{n=1}^{\infty} a_{n} b_{n}=x$. The second assertion is proved in [6, Th. II 6.2,3)].

For every positive integer $n$ and every real $c>0$ we set $r_{n}(c)=$ inf $\|x\|_{X}-1$, where the infimum is taken over all $x \in X$ such that $\left\|U_{k_{n}}(x)\right\|_{X}=1,\left\|x-U_{k_{n}}(x)\right\|_{X} \geqq c$. We set also $r(c)=\inf _{n} r_{n}(c)$. Clearly $r(c)>0$ for all positive $c$. We complete the definition of $r(c)$ by letting $r(0)=0$. In the following we set $V_{k_{n}}(x)=x-U_{k_{n}}(x)$.

LEMma 2. $r(c)$ is a nondecreasing continuous function of $c$.

Proof. Let $\varepsilon>0$ be arbitrarily small and $c_{2}>c_{1} \geqq 0$. There exist $n>0$ and $x \in X$ such that $\left\|U_{k_{n}}(x)\right\|_{X}=1,\left\|V_{k_{n}}(x)\right\|_{X} \geqq c_{2}$ and $1+r\left(c_{2}\right)+\varepsilon>\|x\|_{X} \geqq 1+r\left(c_{1}\right)$. Hence $r\left(c_{2}\right) \geqq r\left(c_{1}\right) \geqq 0=r(0)$ and $r(c)$ is nondecreasing.

Observe now that there exist a sequence of points $x_{j} \in X$ and a sequence of positive integers $n_{j}$ such that

$$
\left\|U_{k_{n_{j}}}\left(x_{j}\right)\right\|_{X}=1, \quad\left\|V_{k_{n_{j}}}\left(x_{j}\right)\right\|_{X} \geqq c_{1} \text { and } 1+r\left(c_{1}\right)+j^{-1}>\left\|x_{j}\right\|_{X} .
$$

We set $v_{j}=\left\|V_{k_{n_{j}}}\left(x_{j}\right)\right\|_{X}$. After extracting a subsequence if necessary, we may suppose that $v=\lim _{j} v_{j}$ exists. If $v>c_{2}$, then, for large values of $j, 1+r\left(c_{1}\right)+j^{-1}>\left\|x_{j}\right\|_{X} \geqq 1+r\left(c_{2}\right)$, so that, by what has been already proved, $r\left(c_{1}\right)=r\left(c_{2}\right)$, and we are done. Thus we may assume $c_{1} \leqq v \leqq c_{2}$. Let $y_{j}=x_{j}+s_{j} V_{k_{n}}\left(x_{j}\right)$, where $s_{j}$ is a scalar such that $\left(1+s_{j}\right) v_{j}=c_{2}$. Clearly we must have $\left\|y_{j}\right\|_{x} \geqq 1+r\left(c_{2}\right)$ and $\left\|x_{j}-y_{j}\right\|_{X}=\left|s_{j}\right| v_{j}$. Hence

$$
\begin{aligned}
1+r\left(c_{1}\right)+j^{-1}>\left\|x_{j}\right\|_{X} & \geqq\left\|y_{j}\right\|_{X}-\left|s_{j}\right| v_{j} \\
& \geqq 1+r\left(c_{2}\right)-\left|s_{j}\right| v_{j}
\end{aligned}
$$

that is,

$$
r\left(c_{2}\right)-r\left(c_{1}\right) \leqq\left|s_{j}\right| v_{j}+j^{-1} \text {. }
$$

Now, if $v<c_{2}$, then $\left|s_{j}\right|=s_{j}=\left(c_{2}-v_{j}\right) v_{j}^{-1} \leqq\left(c_{2}-c_{1}\right) v_{j}^{-1}$ for $j$ large enough. If $v=c_{2}$ then $s_{j}$ tends to 0 , so that, if $j$ is large, $\left|s_{j}\right|<$ 
$\left(c_{2}-c_{1}\right) v_{j}^{-1}$. In any case, for large values of $j$, we obtain $r\left(c_{2}\right)-$ $r\left(c_{1}\right) \leqq\left(c_{2}-c_{1}\right)+j^{-1}$, and the proof is ended.

LEMmA 3. Suppose that $\left(x_{n}\right) \subseteq X$ is a sequence of points converging in the weak* topology to a point $z \in X$. Let $\gamma=$ $\lim \sup _{n}\left\|x_{n}-z\right\|_{X}$. Then, for every $y \in X, y \neq z$

$$
\lim _{n} \sup \left\|x_{n}-y\right\|_{X} \geqq\left\{1+r\left(\gamma\|y-z\| \bar{X}_{X}^{-1}\right)\right\}\|y-z\|_{X}
$$

Proof. Let $\varepsilon>0$ be arbitrarily small. There exists $j=j(\varepsilon)$ such that $\left\|V_{k_{j}}(y-z)\right\|_{x}<\varepsilon$. Since $x_{n}-z$ converges weak ${ }^{*}$ to 0 and the associated functionals $f_{n}$ are weak ${ }^{*}$ continuous (Lemma 1), for every fixed $j$ we can find $n_{0}$ such that $\left\|U_{k_{j}}\left(x_{n}-z\right)\right\|_{X}<\varepsilon$ for $n$ greater than $n_{0}$. Therefore, for $n>n_{0}$, we have by Lemma 2

$$
\begin{aligned}
\| y- & x_{n} \|_{X} \\
& \geqq-2 \varepsilon+\left\|U_{k_{j}}(y-z)+V_{k_{j}}\left(z-x_{n}\right)\right\|_{X} \\
& \geqq-2 \varepsilon+\left\|U_{k_{j}}(y-z)\right\|_{X}\left\{1+r\left(\left.\left\|V_{k_{j}}\left(z-x_{n}\right)\right\|_{X} \cdot\left\|U_{k_{j}}(y-z)\right\|\right|_{X} ^{-1}\right)\right\} \\
& \geqq-2 \varepsilon+\left(\|y-z\|_{X}-\varepsilon\right)\left\{1+r\left(\left(\left\|z-x_{n}\right\|_{X}-\varepsilon\right)\left(\|y-z\|_{X}+\varepsilon\right)^{-1}\right)\right\} .
\end{aligned}
$$

By Lemma 2 again

$\lim \sup \left\|y-x_{n}\right\|_{X}$

$$
\geqq\left(\|y-z\|_{X}-\varepsilon\right)\left\{1+r\left((\gamma-\varepsilon)\left(\|y-z\|_{X}+\varepsilon\right)^{-1}\right)\right\}-2 \varepsilon .
$$

Since $\varepsilon$ is arbitrary and $r$ is continuous, the lemma follows.

3. Main results. The following lemma is a variant of a result of [5].

Lemma 4. Suppose $Y$ is a dual Banach space, $K \subseteq Y$ is a convex weak* compact subset, $T: K \rightarrow K$ is a nonexpansive mapping. Then, for every $x \in K$ there is a closed convex 'subset $H(x) \subseteq K$ which is invariant under $T$ and satisfies

(a) $\operatorname{diam} H(x) \leqq \sup _{n}\left\|x-T^{n} x\right\|_{Y}$

(b) $\sup _{y \in H(x)}\|x-y\|_{Y} \leqq 2 \sup _{n}\left\|x-T^{n} x\right\|_{Y}$.

Proof. For $x \in K$, set $d(x)=\sup _{n}\left\|x-T^{n} x\right\|_{Y}$ and denote by $O(x)$ the orbit of $x$ (i.e., $O(x)=\left\{x, T x, T^{2} x, \cdots, T^{n} x, \cdots\right\}$ ). Set also

$$
A_{0}=\mathrm{cl}^{*} \operatorname{co} O(x) \quad A_{n+1}=\mathrm{cl}^{*} \operatorname{co} T\left(A_{n}\right), \quad n=0,1,2, \cdots
$$

where $\mathrm{cl}^{*}$ co denotes the weak* closure of the convex hull. Clearly $A_{n} \subseteq K, O\left(T^{n+1} x\right) \subseteq T\left(A_{n}\right) \subseteq A_{n+1}, \operatorname{diam} A_{n} \leqq d(x)$. Since $K$ is weak ${ }^{*}$ compact, $B_{k}=\bigcap_{n \geqq k} A_{n}$ is nonvoid for every $k=0,1,2, \cdots$. Moreover $B_{k}$ is closed and convex, $\operatorname{diam} B_{k} \leqq d(x), B_{k} \subseteq B_{k+1}, T\left(B_{k}\right) \subseteq B_{k+1}$. 
It follows that $H(x)=\overline{\mathrm{U}_{k=0}^{\infty} B_{k}}$ satisfies (a). Property (b) follows from the fact that $H(x)$ contains the set $\overline{\bigcap_{n=0}^{\infty} \mathrm{cl}^{*} O\left(T^{n} x\right)}$. It is also clear that $H(x)$ is invariant.

The following theorem is our main result announced in $\S 1$.

TheOREM. Suppose $X$ is a Banach space with a Schauder basis satisfying the assumptions of $\S 1$. Let $Y$ denote an isomorphic Banach space with $t<1+r(1)$. Then, every convex weak* compact subset $K$ of $Y$ has the fixed point property with respect to nonexpansive mappings.

Proof. Suppose $T: K \rightarrow K$ is a nonexpansive mapping. There is a sequence $\left(x_{n}^{0}\right) \subseteq K$ such that $\lim _{n}\left\|x_{n}^{0}-T x_{n}^{0}\right\|_{Y}=0$. After passing to a subsequence if necessary, we may assume that $x_{n}^{0}$ is weak* convergent to a point $z^{0} \in K$, and that $\alpha_{0}=\lim _{n}\left\|x_{n}^{0}-z^{0}\right\|_{Y}$ exists. By nonexpansiveness, for every positive integer $k$ we have $\left\|z^{0}-T^{k} z^{0}\right\|_{Y} \leqq$ $\lim \sup _{n}\left\|x_{n}^{0}-T^{k} z^{0}\right\|_{Y} \leqq \alpha_{0}$. Thus $d\left(z^{0}\right) \leqq \alpha_{0}$. By Lemma 4 there is a closed convex invariant subset $H\left(z^{0}\right) \leqq K$ such that $\operatorname{diam} H\left(z^{0}\right) \leqq \alpha_{0}$. Then there exists a sequence $\left(x_{n}^{1}\right)$ contained in $H\left(z^{0}\right)$ such that $\left\|x_{n}^{1}-T x_{n}^{1}\right\|_{Y}$ tends to $0, x_{n}^{1}$ converges weak* to $z^{1} \in K, \alpha_{1}=\lim _{n} \| x_{n}^{1}-$ $z^{1} \|_{Y}$ exists and also $\gamma_{1}=\lim _{n}\left\|x_{n}^{1}-z^{1}\right\|_{X}$ exists. We then have (recall the notation introduced in $\S 1$ ) for every $m$

$$
\begin{aligned}
& \alpha_{0} \geqq \lim _{n} \sup _{\left\|x_{m}^{1}-x_{n}^{1}\right\|_{Y}} \geqq k^{-1} \lim _{n} \sup _{n}\left\|x_{m}^{1}-x_{n}^{1}\right\|_{X} \\
& \\
& \geqq k^{-1}\left\|x_{m}^{1}-z^{1}\right\|_{X}\left\{1+r\left(\gamma_{1}\left\|x_{m}^{1}-z^{1}\right\|_{X}^{-1}\right)\right\} \\
& \geqq k^{-1} h\left\|x_{m}^{1}-z^{1}\right\|_{Y}\left\{1+r\left(\gamma_{1}\left\|x_{m}^{1}-z^{1}\right\|_{\bar{X}}^{1}\right)\right\}
\end{aligned}
$$

by Lemma 3 . Letting $m$ tend to infinity we get

$$
\begin{aligned}
\alpha_{0} & \geqq \limsup _{m}\left(\lim \sup _{n}\left\|x_{m}^{1}-x_{n}^{1}\right\|_{Y}\right) \\
& \geqq t^{-1} \alpha_{1}(1+r(1))
\end{aligned}
$$

that is,

$$
\alpha_{1} \leqq t(1+r(1))^{-1} \alpha_{0} .
$$

Moreover, since $z^{1}$ belongs to the weak* closure $H\left(z^{0}\right)$, Lemma 4 , (b) implies $\left\|z^{0}-z^{1}\right\|_{Y} \leqq 2 \alpha_{0}$.

Carrying on this process we produce a sequence of nonnegative numbers $\alpha_{n}$ such that $\alpha_{n+1} \leqq t(1+r(1))^{-1} \alpha_{n} \leqq\left\{t(1+r(1))^{-1}\right\}^{n+1} \alpha_{0}$, and a sequence of points $z^{n} \in K$ such that $\left\|z^{n+1}-z^{n}\right\|_{Y} \leqq 2 \alpha_{n},\left\|z^{n}-T z^{n}\right\|_{Y} \leqq$ $\alpha_{n}$. Hence $z^{n}$ is strongly convergent to a fixed point of $T$.

If $X=l^{p}$, it is easy to see that $1+r(1)=2^{1 / p}$. Therefore we have the following remarkable corollary. 
Corollary. Suppose $Y$ is isomorphic to $l^{1}$ with $t<2$. Then every weak* compact convex subset of $Y$ has the fixed point property with respect to nonexpansive mappings.

This corollary generalizes a result of Karlovitz ([3, Corollary]). In [4] an example was given of a space isomorphic to $l^{1}$ with $t=2$, whose unit ball has not the fixed property with respect to nonexpansive mappings. Hence our corollary is the best result possible.

4. Concluding remarks and comparison with previous results. If $X$ is reflexive, then the above theorem can be proved in a much simpler way. This case however is not new, because it is easily seen that, under our assumption on $Y$, every convex weakly compact subset of $Y$ has normal structure. If $X$ is not reflexive, we were not able to decide whether every weak* compact convex subset of $Y$ has normal structure (of course when $t<1+r(1)$ ). Recall that a weak* closed convex subset $C \leqq Y$ has normal structure if every weak* compact convex subset $K \subseteq C$ (containing more than one point) has a nondiametral point (see ([4])). A sufficient condition for $C$ to admit normal structure was also given in [4]. The condition is as follows.

Suppose there exists a functions $\delta:\left(R^{+}\right)^{2} \rightarrow R^{+}$such that

(i) for each fixed $s, \delta(r, s)$ is continuous and strictly increasing

(ii) $\delta(s, s)>s$ for all $s$

(iii) if $x_{n}$ tends to 0 weak $^{*}$ and $\left\|x_{n}\right\|_{Y}$ tends to $s$, then, for all $y \in K,\left\|y-x_{n}\right\|_{Y}$ tends to $\delta\left(\|y\|_{Y}, s\right)$.

It is easy to see that this condition is not satisfied in the space $Y$ obtained by renorming $l^{1}$ with the norm $\|y\|_{Y}=\max \left(\|y\|_{l} \infty\right.$, $\left.t^{-1}\|y\|_{l^{1}}\right)$, where $1<t<2$. Indeed, if $\left(b_{n}\right)$ is the natural basis of $l^{1}$, take $y=b_{1}$. Assume that the condition of [4] is satisfied, say, for the unit ball of $Y$. We have $\|y\|_{Y}=1$. Set $x_{n}=(t-1) b_{n}$. Then $\left\|x_{n}\right\|_{Y}=t-1,\left\|y-x_{n}\right\|_{Y}=1$, so that, by (iii), $\delta(1,(t-1))=1$. On the other hand, if we choose $z=b_{1}+(t-1) b_{2}$, we have $\|z\|_{Y}=1$ and $\left\|z-x_{n}\right\|_{Y}=t^{-1}\left\|z-x_{n}\right\|_{l^{1}}=t^{-1}(2 t-1)$. Hence, by (iii) we should have $\delta(1, t-1)=2-t^{-1}$, a contradiction.

Analogous arguments show also that the relation $\perp$ is not approximately uniformly symmetric in $Y$ (in the sense of [3]) and our result cannot be deduced from [3].

For other examples concerning spaces $X$ satisfying our assmuptions, we refer to [2] and [6].

\section{REFERENCES}

1. W. L. Bynum, Normal structure coefficients for Banach spaces, Pacific J. Math., 86 (1980), 427-436. 
2. P. Gossez and E. Lami Dozo, Sructure normale et base de Scauder, Bull. Cl. Sc. Ac. R. Belgique, 55 (1969), 673-681.

3. L. A. Karlovitz, On nonexpansive mappings, Proc. Amer. Math. Soc., 55 (1969), 321-325.

4. T. C. Lim, Asymptotic centers and nonexpansive mappings in some conjugate spaces, preprint.

5. D. Roux and Paolo M. Soardi, Alcune generalizzazoni del teorema di Browder-GöhdeKirk, Atti Accad. Naz. Lincei, Rend. Cl. Sc. Mat. Fis. Nat., 52 (1972), 424-430.

6. I. Singer, Bases in Banach Spaces I, Springer Verlag, Berlin, Heidelberg, New York, 1970.

Received August 17, 1980.

Universita di Milano

"Federigo Enriques"

Via c Saldini, 50

20133 Milano, Italy 


\section{PACIFIC JOURNAL OF MATHEMATICS}

\section{EDITORS}

DONALD BABBITT (Managing Editor)

J. DUGUNDJI

University of California

Los Angeles, California 90024

Hugo Rossi

University of Utah

Salt Lake City, UT 84112

C. C. Moore and Arthur Agus

Department of Mathematics

University of Southern California

Los Angeles, California 90007

R. FinN and J. Milgram

Stanford University

Stanford, California 94305

University of California

Berkeley, CA 94720

\section{ASSOCIATE EDITORS}
R. ARNES
E. F. BeCKenBaCH
B. H. NEUMANN
F. WoLF
K. YoshidA

\section{SUPPORTING INSTITUTIONS}

UNIVERSITY OF ARIZONA

UNIVERSITY OF BRITISH COLUMBIA

CALIFORNIA INSTITUTE OF TECHNOLOGY

UNIVERSITY OF CALIFORNIA

MONTANA STATE UNIVERSITY

UNIVERSITY OF NEVADA, RENO

NEW MEXICO STATE UNIVERSITY

OREGON STATE UNIVERSITY
UNIVERSITY OF OREGON

UNIVERSITY OF SOUTHERN CALIFORNIA

STANFORD UNIVERSITY

UNIVERSITY OF HAWAII

UNIVERSITY OF TOKYO

UNIVERSITY OF UTAH

WASHINGTON STATE UNIVERSITY

UNIVERSITY OF WASHINGTON 


\section{Pacific Journal of Mathematics}

\section{Vol. 101, No. $1 \quad$ November, 1982}

Natália Bebiano, On the evaluation of permanents $\ldots \ldots \ldots \ldots \ldots \ldots \ldots \ldots$

David Borwein and Bruce Brigham Watson, Tauberian theorems between

the logarithmic and Abel-type summability methods $\ldots \ldots \ldots \ldots \ldots \ldots 11$

Leo George Chouinard, II, Hermite semigroup rings $\ldots \ldots \ldots \ldots \ldots \ldots \ldots$

Kun-Jen Chung, Remarks on nonlinear contractions $\ldots \ldots \ldots \ldots \ldots \ldots . \ldots 4$

Lawrence Jay Corwin, Representations of division algebras over local

fields. II ......................................... 49

Mahlon M. Day, Left thick to left lumpy—a guided tour $\ldots \ldots \ldots \ldots \ldots 71$

M. Edelstein and Mo Tak Kiang, On ultimately nonexpansive

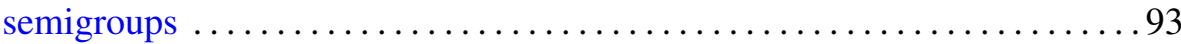

Mary Rodriguez Embry, Semigroups of quasinormal operators . ........ 103

William Goldman and Morris William Hirsch, Polynomial forms on

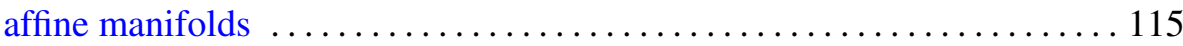

S. Janakiraman and T. Soundararajan, Totally bounded group topologies

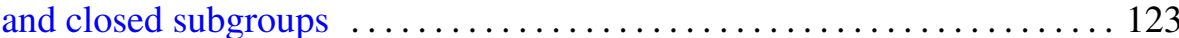

John Rowlay Martin, Lex Gerard Oversteegen and Edward D.

Tymchatyn, Fixed point set of products and cones $\ldots \ldots \ldots \ldots \ldots \ldots 133$

Jan van Mill, A homogeneous Eberlein compact space which is not metrizable ........................................ 141

Steven Paul Plotnick, Embedding homology 3-spheres in $S^{5} \ldots \ldots \ldots \ldots 147$

Norbert Riedel, Classification of the $C^{*}$-algebras associated with minimal rotations

Benedict Seifert, Combinatorial and geometric properties of weight systems of irreducible finite-dimensional representations of simple split Lie algebras over fields of 0 characteristic

James E. Simpson, Dilations on locally convex spaces

Paolo M. Soardi, Schauder bases and fixed points of nonexpansive mappings

Yoshio Tanaka, Point-countable $k$-systems and products of $k$-spaces

Fausto A. Toranzos, The points of local nonconvexity of starshaped sets . . . 209

Lorenzo Traldi, The determinantal ideals of link modules. I . . . . . . . . 215

P. C. Trombi, Invariant harmonic analysis on split rank one groups with applications

Shinji Yamashita, Nonnormal Blaschke quotients 